\title{
Seis incógnitas y algunas respuestas sobre la vida de Fray Tomás de Mercado
}

\author{
Manuel J. LAGARES CALVO \\ Universidad de Alcalá ${ }^{1}$
}

Entre el grupo de filósofos de la llamada "Escuela de Salamanca" destaca Fray Tomás de Mercado con su Suma de tratos y contratos. Esta obra es, probablemente y en el ámbito de la economía, una de las mejor conocidas en su tiempo y una de las que todavía hoy se consideran más notables de las escritas por este grupo de filósofos y teólogos de los siglos XVI y XVII.

La conjunción de un conocimiento vivo y directo de la trepidante realidad económica del momento (siglo XVI) con la vieja casuística escolástica singulariza y distingue a la obra de Mercado y, en general, a la de los miembros de la Escuela de Salamanca frente a las de sus antecesores medievales y a las de sus coetáneos de otros países europeos. Velarde ha descrito muy bien esa realidad y su ambiente al señalar que:

a finales del siglo XV y comienzos del XVI tuvo lugar un cambio fundamental en el funcionamiento de la economía. Por una parte, los descubrimientos y conquistas de los españoles habían dado lugar, por vez primera desde el inicio de la Humanidad, a la existencia de una economía mundial. Alrededor de la plata americana se alzaron las avideces chinas y las necesidades europeas, y en torno a eso se tejieron relaciones que iban de Potosí a Sevilla, Génova y Amberes, y también de Potosí o de México a Acapulco, Manila y Pekín. Precios, tipos de interés, desarrollos materiales, se determinaban por este entrecruzamiento de relaciones económicas de todo tipo... En el triángulo Sevilla, Lisboa y Amberes se concentró la riqueza, incluso la opulencia, de esa nueva economía mundial. La transformación también se debió a la aparición de nuevas instituciones que hicieron posible que el capitalismo irrumpiese entre nosotros, con fuerza, por primera vez y para siempre. La partida doble o la letra de cambio son algunas de estas novedades”. [Velarde, Juan, 2002, “La escuela de Salamanca y José Larraz", La ilustración liberal. Revista española y americana, n. 11, junio]

Las gradas de la Catedral de Sevilla, su Casa de Contratación y su puerto en el Guadalquivir, tan próximos al Colegio-Universidad de Santo Tomás, donde residiría Mercado durante sus estancias en Sevilla como teólogo, hervían con esa nueva actividad e igual ocurría en la Nueva España y en el Perú.

Los escolásticos habían venido derivando de Aristóteles y de Santo Tomás sus criterios y principios, que aplicaban luego a las consultas del confesionario y a las cuestiones que daban origen a sus informes y "decisiones". Pero el catolicismo parecía entrar en contradicción con todo este mundo nuevo, pues según San Antonino, "si algún comerciante ejerce su arte no para un fin honesto, como el gobierno de la familia, la utilidad de la patria, u otro parecido, sino movido de un deseo de incrementar la riqueza, al cometer torpe lucro incurre en un grave pecado".

\footnotetext{
${ }^{1}$ Este trabajo tiene su origen y constituye una ampliación más sistematizada de una de las partes de mi estudio sobre "La huella de un sevillano en el pensamiento económico actual" referido a Tomás de Mercado y su obra, publicado en Economía y economistas andaluces (Sánchez Lissen, R. Madrid, Ecobook, 2013). Me ha animado a escribirlo la reciente publicación en facsímil de la primera edición (1569) de la obra de Mercado (Tratos y Contratos de Mercaderes y Tratantes. Ediciones de la Universidad de Salamanca. Salamanca, 2015) que constituye una auténtica joya bibliográfica por sí misma y que se completa y perfecciona además con tres excelentes estudios introductorios: el de Francisco Gómez Camacho ("Tomás de Mercado, O.P.: Suma de Tratos y Contratos"); el de Antonio-Miguel Bernal ("Tomás de Mercado y las 'negociaciones' con las Indias") y, finalmente, el de Margarita Becedas González ("La edición salmantina de Matías Gast y el ejemplar de la Universidad de Salamanca"). Estoy seguro de que a los estudiosos de las raíces españolas del pensamiento económico y a los bibliófilos les interesará muy particularmente esta nueva publicación de la Universidad de Salamanca y de que tampoco les vendrá mal un repaso sistematizado de lo que hoy conocemos y de lo que todavía ignoramos acerca de Fray Tomás de Mercado.
} 
Tomás de Mercado no se enfrentará de forma directa con tan dura sentencia e, incluso, la aceptará de forma casi literal, pero en el análisis de la conducta de los comerciantes en los tratos y contratos de su Suma encontrará huecos suficientes para, sin renunciar aparentemente a los principios de la escolástica medieval, dar entrada y justificar moralmente muchos de los aspectos de ese mundo nuevo y extraordinariamente cambiante, con instituciones que difícilmente podían entenderse solo con los instrumentos del pasado. Ese mundo, como ya se ha expuesto, desplegaba una fuerte intensidad en sus relaciones comerciales y una extensión de su ámbito geográfico como nunca antes se había conocido, en el que se veía implicado tanto el viejo continente en su conjunto como las nuevas tierras americanas, con sus grandes riquezas de oro y plata y sus enormes penurias en bienes materiales de todo tipo.

Las nuevas circunstancias descritas tenían que dar paso a un cambio bien perceptible en la consideración de la actividad económica y de sus instituciones, constreñidas hasta entonces por las antiguas normas y doctrinas. De ese amplio mestizaje de la escolástica medieval con el análisis de instituciones que empujaban hacia planteamientos nuevos nació la metodología de la "Escuela de Salamanca", libre de algunas de las ataduras del pasado pero todavía tributaria de otras muchas, aunque el cambio resultaba evidente. Es en ese ambiente de cambio y renovación donde hay que encuadrar la Suma de Fray Tomás de Mercado, con una originalidad y frescura fácilmente perceptibles en todas sus páginas, lo que condujo a su amplia difusión y a su perceptible influencia en el pensamiento económico durante un periodo que se extiende desde las últimas décadas del XVI hasta casi finales del XVII y, aunque ya no tan directamente, incluso hasta la primera mitad del siglo XVIII.

Ese amplio conocimiento y fuerte influencia de la Suma de tratos y contratos contrasta, sin embargo, con el escaso conocimiento que se tenía respecto a la vida de su autor, Fray Tomás de Mercado, que venía siendo hasta hace bien poco casi un completo desconocido. Las noticias sobre su vida se limitaban a que había sido sacerdote y miembro de la Orden de Predicadores (dominicos) y a las escasas informaciones proporcionadas por Fray Agustín Dávila Padilla en 1625, cincuenta años después de su fallecimiento. De ahí que resulte de interés profundizar algo más en su vida, sistematizando lo hasta ahora conocido y lo que el autor ha podido ampliar por el momento.

Son muchas las incógnitas que rodean esa vida, pero quizá las más importantes para entender mejor el sentido y la orientación de la obra de Fray Tomás de Mercado sean, al menos, seis. La primera, desde luego, es la que hace referencia a su nombre civil. La segunda -en nuestra opinión ya definitivamente resuelta- se refiere al lugar de su nacimiento. La tercera es la de su fecha de nacimiento. La cuarta, la de si Mercado fue comerciante antes que fraile. La quinta, la de los motivos que le llevaron a su profesión religiosa y a los estudios que realizó. Y la sexta y última, la de las razones que le impulsaron a emprender el viaje de su vuelta a México, truncado por su muerte casi al final del mismo.

\section{Nombre civil de Fray Tomás de Mercado}

No deja de sorprender un tanto que quien, con hábitos de fraile dominico y conocimientos propios de comerciante, escribiese la Suma de Tratos y Contratos aplicando principios escolásticos a esa realidad, tuviese por nombre Tomás de Mercado. Comenzando por el nombre propio, Tomás es también el nombre de Santo Tomás de Aquino, sin duda el más célebre de los dominicos, el máximo exponente del escolasticismo y, por si fuese poco, autor de la Summa Theologiae, es decir, del más célebre tratado de teología de la Historia. Siguiendo por el apellido, no puede negarse que "de Mercado" sería un patronímico muy apropiado para quien hubiese abandonado su profesión de comerciante para ingresar en un convento.

No solo existe la apariencia de toda una completa y oculta intencionalidad en el nombre y apellido religioso de Fray Tomás de Mercado sino que, además, existe también un evidente paralelismo entre el título de la obra más importante de Santo Tomás - la citada Summa Theologiae- y el de la obra más importante de Mercado en su segunda y definitiva edición (Suma de Tratos y Contratos). Eso induce a creer que Tomás de Mercado sentía una piadosa devoción hacia Santo Tomás, al que consideraba su maestro y guía en la vida religiosa, lo que podría servir para reforzar la hipótesis de un posible cambio de nombre al ingresar en religión, aunque la decisión de denominar Suma a la segunda edición de su obra (1571) solo se tomó por Mercado 
cuando escribió su ampliación, es decir, bastantes años después de la posible elección de su nombre religioso (1553). El nombre definitivo de su obra puede, quizá, constituir otra prueba más de su admiración por Santo Tomás de Aquino y, en ese sentido, podría reforzar la hipótesis de que tal admiración por Santo Tomás hubiese sido el motor que le pudo impulsar, muchos años antes, a elegir para su vida religiosa el nombre de "Tomás de Mercado" distinto a su verdadero nombre civil, desconocido por ahora. Además, el hecho de que, pese a su exhaustiva búsqueda por el autor, no se haya podido encontrar en el Archivo General de Indias el registro de su primer viaje a México, cuando aún no había ingresado en el convento, abonaría la hipótesis de que ese primer viaje lo hizo bajo un desconocido nombre civil.

¿Es, por tanto, "Tomás de Mercado" un nombre adoptado al profesar en religión, según costumbre frecuente entre los religiosos regulares, o es el propio nombre civil de nuestro protagonista? Esta es, sin duda, la primera de las varias incógnitas que se plantean respecto a Tomás de Mercado.

Como acaba de indicarse, no cabe duda de que admitir que "Tomás de Mercado" no es más que un nombre religioso pero no civil permitiría, además, justificar fácilmente que no se hubiese encontrado en el Archivo de Indias bajo ese nombre el registro correspondiente al primer viaje de Mercado de Sevilla a México. Pero ese posible argumento pierde mucha de su fuerza si se tiene en cuenta, en primer término, que los registros de pasajeros a las Indias correspondientes al periodo 1541-1552 son casi inexistentes y es en ese periodo cuando muy probablemente Mercado marchase por primera vez a América. Y, en segundo lugar, porque en el referido Archivo existen numerosos documentos de aquellos años relativos a Diego, Pedro, Francisco, Jerónimo, Bernardino y otros muchos "de Mercado". Es decir, fueron muchos los "de Mercado" relacionados con América o viajeros a aquellas tierras en tales años, solos o acompañados de otros familiares pero sin que los nombres de estos últimos estuviesen especificados en la mayoría de esos registros. Quizá alguno de esos registros se refiriese a los nombres de los parientes que llevasen a Tomás de Mercado a América por primera vez, quedando sin embargo oculto el nombre de nuestro protagonista por las deficiencias y rutinas del registro. Además el patronímico "Mercado" existía en Sevilla al menos desde finales del siglo XV o principios del XVI. Si no se ha encontrado el registro concreto de su viaje inicial a México bajo ese nombre, lo más probable es que se deba, como ya se ha expuesto, a las insuficiencias de tales registros entre $1541 \mathrm{y}$ 1552.

Esas razones parecen indicar que no hay fundamentos sólidos para inclinarse por la hipótesis de que "Tomás de Mercado" fuese tan solo un nombre religioso pero no civil. De ahí que, mientras no se disponga de pruebas documentales en contrario, el nombre de "Tomás de Mercado" ha de considerarse como el verdadero nombre civil de nuestro fraile al tiempo que su nombre religioso.

\section{Lugar de su nacimiento}

Ha llegado a ponerse en duda también que Fray Tomás de Mercado hubiese nacido en Sevilla, situando ese nacimiento en América. Esta opinión que localiza el nacimiento de Mercado en la Nueva España, hoy México, se ha venido fundamentando en el "Índex" de Nicolás Antonio donde se encuentra una oscura frase: "Thomas de Mercado. Ex Regno Mexicano". Esa frase no significa literalmente que Fray Tomás de Mercado hubiese nacido en México sino que venía o procedía de México, lo que era plenamente cierto, o que su vida había discurrido en México, lo cual es ya algo más discutible. Hay que señalar que Nicolás Antonio, miembro de la Compañía de Jesús y nacido en Sevilla, escribe esa frase en 1672, prácticamente un siglo después de la muerte de Fray Tomás de Mercado (1575), sin apoyarla en fuentes documentales que señalasen tal nacimiento en México.

Basándose en la nota de Nicolás Antonio, Wilhelm Weber sostuvo en 1962 el nacimiento mexicano de Mercado señalando que "era mejicano de nacimiento" y que murió cuando volvía "a su patria mejicana" pero tampoco indica las fuentes en que fundamentaba tales aseveraciones. También Oreste Popescu cree que el nacimiento de Mercado se produjo en Nueva España, pero limitándose a citar la opinión de los dos autores anteriores, en los que apoya la suya. Por tanto, solo Wilhem Weber mantuvo, por opinión propia y buscando apoyo en la oscura frase de Nicolás Antonio, que Mercado nació en Nueva España. Siguiendo esa opinión, Oreste Popescu 
incluyó a Mercado entre los integrantes de la "escolástica indiana" refiriéndose solo a los autores anteriormente mencionados para considerar a Mercado como natural de la Nueva España sin otro fundamento que la confusa referencia inicial de Nicolás Antonio.

Es evidente, por tanto, que la hipótesis del nacimiento de Mercado en Nueva España se sustenta en interpretaciones y citas sucesivas de la frase de Nicolás Antonio, sin otro soporte que la referida cita, lo que no ocurre con la opinión de un Tomás de Mercado "natural de Sevilla". Esta última adscripción cuenta hoy con un irrebatible fundamento documental bien probado gracias a la minuciosa investigación de Lázaro Sastre Varas en los Libros de Matrícula de la Universidad de Salamanca y también a la que el autor ha realizado en el Archivo General de Indias. En Salamanca existen anotaciones, repetidas en cada curso, del tenor literal siguiente: "Fr. Thomas de Mercado, natural de Sevilla, presbítero y teólogo". En el Archivo General de Indias hemos podido comprobar que el asiento correspondiente al embarque de Mercado de vuelta a México el 25 de octubre de 1574 dice literalmente: "El Maestro Fray Tomás de Mercado, dominico, natural de Sevilla, a Nueva España". El asiento del Archivo General de Indias y las anotaciones de los Libros de Matrícula de Salamanca responden a manifestaciones personales y directas del propio Mercado, que se declara literalmente "natural de Sevilla" en todas ellas, lo que constituye una reiterada confesión de parte sobre su nacimiento en esa ciudad frente a la débil hipótesis mexicana, que no cuenta con soporte documental alguno.

Hay que concluir, por tanto, que hoy se sabe con seguridad que Tomás de Mercado era natural de Sevilla. Así lo declara reiteradamente él mismo cuando se matricula en los diversos cursos que recibió como doctorando en la Universidad de Salamanca. En todas y cada una de sus sucesivas matrículas en la Universidad salmantina Mercado declara ser "natural de Sevilla". Igualmente se declara "natural de Sevilla" en el último documento oficial relativo a su persona conocido hasta el momento. No cabe, pues, dudar de su nacimiento en Sevilla ante tan reiteradas y documentadas confesiones propias, sin que exista ninguna otra en la que el propio Mercado diga ser natural de la Nueva España, de la ciudad de México o de cualquier otro lugar.

\section{Fecha de su nacimiento}

Tampoco se conoce hasta ahora la fecha del nacimiento de Fray Tomás de Mercado. Algunos como Ibarguengoitia afirman que Mercado nació en el año de 1523. Otros como Sánchez Albornoz se inclinan por el año de 1530.

Si se parte de la fecha de 27 de abril de 1553, en la que Tomás de Mercado hizo su profesión religiosa en el Convento de Santo Domingo de México recibiendo la primera orden (acólito), es posible estimar que ingresase en el citado Convento en 1551 o en 1552, es decir, uno o dos años antes. Si ese ingreso lo hubiese hecho a la edad habitual de veinte o veintiún años, podría mantenerse sin mayores problemas que Mercado nació en las proximidades de 1530, que es la hipótesis antes citada de Sánchez Albornoz.

Sin embargo Sastre Varas cree -en nuestra opinión, con mayor fundamento- que Mercado ingresó en el Convento con más edad y madurez que la de veinte o veintiún años, pues recibió las distintas órdenes eclesiásticas con inusitada rapidez. Así en 1553 es ordenado acólito, en 1555 subdiácono, en 1556 diácono y en 1558 accede al sacerdocio, lo que exigía, como requisito indispensable, un buen conocimiento del latín y, sobre todo, superar el riguroso examen que la Orden de Predicadores hacía sistemáticamente para conocer los motivos, la intención y, especialmente, la madurez de los candidatos al sacerdocio.

Además ha de tenerse en cuenta que Tomás de Mercado, como mantiene Oswaldo Robles y prueban sus obras en latín y sus traducciones de Aristóteles, conocía muy bien el latín y el griego. Por eso es bastante probable que esa rapidez en su carrera eclesiástica se debiese a que cuando ingresó en el Convento en 1551 o 1552 era ya buen conocedor de esas lenguas y, además, persona formada, suficientemente madura y con una motivación o vocación religiosa claramente definida. Por eso es muy posible que Mercado hubiera nacido en Sevilla algo antes de 1520 , con lo que ingresaría en el convento con algo más de treinta años (1551 o 1552) y ya con amplios conocimientos de las lenguas clásicas.

Esa fecha de nacimiento (algunos años antes de 1520) permitiría suponer que Mercado habría recibido una buena educación durante su niñez y juventud en su Sevilla natal, estudiando en profundidad griego y latín. Su marcha a México debería situarse, por tanto, a partir de 1540 -es 
decir, no mucho después de cumplidos los veinte años- y antes de 1550, aunque en el Archivo General de Indias no se hayan encontrado referencias directas de este primer viaje a América por las razones ya expuestas y pese a la intensa búsqueda que hemos efectuado a este respecto.

Todo lo anterior se reforzaría notablemente si se demostrase, como se discutirá seguidamente, que Mercado fue comerciante en Sevilla antes de ingresar en el convento en México. De ser así, el viaje de Mercado a Nueva España tendría que haberlo hecho probablemente con más de veinte años de edad, muy probablemente para actuar como factor de su familia y continuar allí los negocios de esta en Sevilla. Por eso se estima que nació en 1520 o algo antes y que su primer viaje a Nueva España debió efectuarse probablemente a partir de 1540 y antes de 1550.

Esa hipótesis sobre la fecha de su nacimiento acota mejor la vida de Fray Tomás de Mercado, pues la publicación de su Suma en 1569 -primera edición - la habría realizado en las proximidades de los 50 años de edad, es decir, ya en plena madurez intelectual. Su muerte en 1575 supondría una vida de algo más de 55 años, no demasiado fuera de lo común en aquellos tiempos teniendo en cuenta, además, las especiales circunstancias en que se produjo su fallecimiento. Conviene insistir, no obstante, en que la fecha de su nacimiento, lo expuesto sobre su educación previa al ingreso en el Convento y la fecha de su primer viaje a México no son más que hipótesis con suficiente fundamento en nuestra opinión, aunque les falte por ahora un explícito apoyo documental.

\section{4. ¿Había sido comerciante Fray Tomás de Mercado?}

Otro aspecto que parece no totalmente aclarado en la vida de Fray Tomás de Mercado es el relativo a la forma en que adquirió el profundo conocimiento que demuestra en su obra respecto a los tratos y contratos de los comerciantes y a la forma en que se desarrollaba el comercio y los cambios entre las diferentes ciudades y partes del mundo. Para algunos, como Nicolás Sánchez Albornoz, esos conocimientos eran el resultado de largas horas de confesionario, de las "decisiones" que hubo de redactar respecto a las cuestiones y consultas que se le plantearon sobre la moralidad de tales tratos y contratos e, incluso, de la experiencia "de la comunidad religiosa a la que pertenecía", conforme a la opinión de Dávila Padilla que reproduce Sánchez Albornoz, subrayando, al mismo tiempo, que "la prosa de Mercado descubre bajo la toga del maestro en Sagrada Teología el hábito talar del fraile andariego". Pero, en nuestra opinión, esa prosa manifiesta con gran nitidez más que al fraile andariego, el dominio de quien probablemente nació en el seno de una familia de comerciantes de Sevilla y había practicado esa profesión en su juventud en Sevilla e incluso después, durante sus primeros años de estancia en la Nueva España, antes de ingresar en el Convento.

La tesis de que Mercado fue comerciante antes que fraile se avala, antes que nada, por el excepcional conocimiento que demuestra en la Suma respecto a las intrincadas prácticas comerciales de su época. Ese conocimiento no se pudo derivar solo de las consultas y descripciones que le llegaban a través del confesionario con las opiniones de los penitentes, siempre bien disfrazadas y adobadas por el deseo de legitimar en conciencia sus propias conductas, sino por un conocimiento directo de las instituciones -los tratos y contratos- a través de sus propias experiencias personales, porque los dominicos en México observaban estrictamente la clausura y no estaban autorizados ni a salir al patio de su recinto . Por eso tal conocimiento tuvo probablemente que derivarse del ejercicio, intenso y razonablemente duradero, de la profesión de comerciante en Sevilla y en América, antes de su ingreso en el Convento. Esta opinión cuenta con el apoyo, en primer término, de una auténtica confesión, aunque encubierta, del propio Mercado y, en segundo lugar, del juicio claro y rotundo que Mercado mantuvo en su obra respecto a la posibilidad de una valoración moral acertada de las instituciones y prácticas mercantiles de su época.

Comenzando por la confesión encubierta, esta se manifiesta por Mercado al relatar una anécdota acaecida "a un mercader, que ahora es religioso ordinis Predicatorum" - el subrayado es nuestro- con un esclavo negro que vendió y que declaró libre la Audiencia Real al demostrarse que, al tiempo que lo hicieron esclavo y lo embarcaban en África, daba grandes voces de protesta y forcejeaba hacia atrás, lo que probaba que su esclavitud no había sido voluntaria sino forzada". Es muy posible que, al relatar ese suceso, Mercado estuviese refiriéndose a algo que le hubiese acontecido personalmente a él mismo, cuando era todavía comerciante, en opinión bien fundada de Sastre Varas porque en la Nueva España solo hubo por aquellas fechas otros dos 
miembros de la Ordinis Predicatorum que hubiesen sido comerciantes con anterioridad a su ingreso en el Convento y, por tanto, a los que les hubiera podido ocurrir el referido suceso. Sin embargo, Sastre Varas prueba que uno de esos dos clérigos ya había muerto cuando Mercado escribe "que ahora es religioso ordinis Predicatorum" y que el otro era un lego muy tímido y subordinado que, debido a la diferencia de grados en las órdenes religiosas recibidas y a la estricta separación que entre esas órdenes mantenían habitualmente los dominicos, no debió tener apenas relación verbal con el presbítero Mercado.

La opinión rotunda de Mercado acerca del necesario conocimiento de las instituciones y prácticas mercantiles de su época para enjuiciarlas acertadamente se manifiesta sin tapujos cuando dice que “... pareceres veía yo [...] de hombres eminentísimos en letras que no daban ni tocaban el punto por solo que no se les hacía clara y distinta información del negocio [...] a cuya causa siempre juzgué por imposible juzgar de oídas acertadamente...”. La opinión de Mercado es rotunda: para "tocar el punto" - es decir, para acertar con lo fundamental de la cuestión y no enredarse en lo accesorio- no se puede "juzgar de oídas acertadamente", es decir, formando criterio exclusivamente de las consultas y descripciones que le llegaban a través del confesionario porque, como ya se ha expuesto, esas consultas y descripciones de los penitentes, aparte de ser fragmentarias y parciales, solían venir disfrazadas por el deseo de legitimar en conciencia sus propias conductas. Todo lo cual hace pensar fundadamente que Mercado creería también que él mismo no sería capaz de opinar acertadamente juzgando tan solo de oídas. Como juzga muy frecuentemente las prácticas de los comerciantes, hay que concluir que no lo haría de oídas, sino por personal y directo conocimiento de tales prácticas. Eso permite fundamentar mejor todavía que, antes de ser fraile, Mercado había ejercido de comerciante o había pertenecido a una familia de comerciantes y conocido de primera mano los tratos y contratos de los mercaderes.

Por otra parte, también resulta interesante comprobar otro fundamento, aunque circunstancial, de la opinión que acaba de exponerse. Tanto en su primera edición (Salamanca) como en su segunda y definitiva (Sevilla), la "Suma" está dedicada "Al insigne y célebre Consulado de Mercaderes de Sevilla" y que, además, en la "Epístola nuncupatoria", que la introduce y justifica, el propio Mercado manifiesta que "residiendo los años pasados en esta ciudad (se refiere a Sevilla) Angelo Brunengo, hombre cursado desde su mocedad en los negocios de esas gradas, me compelió con buenas razones a poner en orden y estilo claro muchas decisiones de casos tocantes a mercaderes que en diversos tiempos y lugares había dado casi en todas materias de sus tratos, así viviendo en Nueva España como en esta Universidad" . Angelo Brunengo, nombre de raigambre genovesa, fue personaje importante en la Sevilla de la época, ocupando cargos de relieve en el Consulado de Mercaderes de la ciudad y en su Casa de la Contratación, como puede comprobarse por los asientos del Archivo General de Indias que hemos podido encontrar.

La amistad entre Mercado y Ángelo Brunengo parece evidente en la interesante cita de la "Epístola nuncupatoria" al señalar que "me compelió con buenas razones" para que escribiese la "Suma". Esa cita deja entrever una relación entre ellos o entre sus respectivas familias probablemente anterior al viaje inicial de Mercado a México, pues resulta poco fundado que esa relación se hubiese desarrollado únicamente en el corto periodo que discurre entre el verano de 1564 y el otoño de 1566 en que Mercado vivió en Sevilla antes de volver a Salamanca y publicar la primera edición de la "Suma" en que ya cita a Brunengo.

Para fijar mejor el posible origen de ese conocimiento no debería perderse de vista, además, la importancia de Angelo Brunengo en la Sevilla de entonces y el escaso relieve social que le habría correspondido al fraile Tomás de Mercado de no haber contado él mismo con el apoyo e influencia del paronímico de su burguesa familia en una ciudad por aquellos tiempos colmada de frailes y con una fuerte estratificación de clases sociales. Difícilmente puede entenderse la relación Mercado-Brunengo de no ocupar Mercado en Sevilla una posición de más relieve social que la que le hubiese correspondido como simple fraile estudiante en Salamanca, sobre todo sin haber alcanzado todavía grado académico alguno ni haber publicado ninguna obra en aquellos momentos. Por sí mismo, Mercado no era mucho más que eso -un simple fraile, aunque instruido- antes de que hubiese alcanzado el grado de Maestro en Teología y le hubiese llegado la fama que le reportó posteriormente la publicación de la "Suma". Por eso su conocimiento y 
amistad con Ángelo Brunengo debió ser bastante anterior a la primera edición de esa obra (1569), en la que se cita a este último como su inductor. De ahí que la hipótesis más plausible sea la de considerar que la relación de Mercado con personaje tan importante como Angelo Brunengo viniera de antes de su primer viaje a México o que se fundamentase en un conocimiento anterior de sus respectivas familias, lo que además corroboraría que Mercado procedía de una familia acomodada de Sevilla, que pudo ser comerciante o factor de comerciante antes de su marcha a México y que quizá, incluso, continuase desempeñando esa profesión en sus primeros tiempos de estancia en América antes de su ingreso en el Convento.

Una última y muy débil prueba, también circunstancial, puede reforzar la hipótesis de que Tomás de Mercado había adquirido sus conocimientos sobre la actividad de los mercaderes por propio ejercicio de esa profesión y no a través del confesionario. Como minuciosamente describe Félix González de León la Iglesia del Colegio de Santo Tomás de Sevilla, "no era pública y estaba dentro del claustro. Se entraba por un pequeño zaguán, y al lado derecho se hallaba un pequeño patio y en él la puerta de la Iglesia que era poco más que una sala particular, aunque tenía coro alto...”. En ella se rezaba el Oficio canónico y se celebraba el Santo Sacrificio, pero no tenía ni púlpito ni confesionarios.

\section{Vocación religiosa y estudios de Tomás de Mercado}

No se conocen las causas de la vocación religiosa de Fray Tomás de Mercado ni por qué eligió la Orden de Predicadores para materializarla. Partiendo de que su ingreso en el Convento en México muy probablemente se produjo cumplidos ya sus treinta años de edad y quizá después de haber ejercido la profesión de comerciante, cabe pensar que esa vocación se despertaría tardíamente, quizá por la sublimación de su espíritu piadoso con la edad o por la influencia directa de algún desconocido e importante hecho emocional que tuviese fuerte impacto en su vida y que le pudo conducir a cambiar radicalmente la que hasta entonces había llevado, pero esto no constituye más que meras hipótesis sin soporte documental alguno.

En lo relativo a la Orden elegida, solo cabe conjeturar si esa decisión no habría estado influida por la posible formación durante su infancia y juventud en Sevilla en el Colegio de Santo Tomás, al que luego volvería , como más adelante se expone, para alcanzar el grado de Maestro en Sagrada Teología durante sus posteriores estancias en esa ciudad. También es posible que esa decisión estuviese también motivada por la fama del Convento de los dominicos de México, donde habían llegado unos años antes personajes tan importantes como Fray Pedro de Pravia, Fray Pedro de la Peña y Fray Diego de Osorio, formados en la Universidad de Salamanca. A ello podría unirse la facilidad que ofrecería ese Convento a un antiguo colegial de los dominicos de Sevilla. Quizá, además, esta última circunstancia facilitó a Fray Tomás de Mercado su rápida carrera eclesiástica, pasando del grado de acólito al de presbítero en solo cinco años. Pero hay que insistir en que todo ello no es más que una hipótesis no documentada, igual que la relativa al posible despertar de su vocación religiosa.

En cuanto a sus estudios, ya se ha visto que muy probablemente Fray Tomás de Mercado inició su formación durante su infancia en Sevilla, en el Colegio de Santo Tomás, que mantenía la Orden de Predicadores. Durante su estancia en México su formación se realizó en el Convento de los dominicos de esa ciudad y, como acaba de verse, con los ya citados Fray Pedro de Pravia, Fray Pedro de la Peña y Fray Diego de Osorio, procedentes de la Universidad de Salamanca. Sus estudios posteriores se realizaron en la Península y, muy probablemente, en el Colegio de San Estaban de esa última Universidad. Su estancia en Salamanca está documentalmente probada por los libros de matrícula ya comentados y por la primera edición su obra (1569), que se publica bajo el título de Tratos y contratos de mercaderes y tratantes. En la portada de esta primera edición se indica que el autor es "el Padre Presentado Fray Thomas de Mercado, de la orden de los Predicadores". Como ya se ha comentado, la segunda y definitiva edición de esta obra publicada en Sevilla en 1571, está muy ampliada respecto a la primera y aparece bajo el título de Suma de Tratos y Contratos. En la portada se indica que ha sido "compuesta por el muy Reverendo Padre Fray Thomas de Mercado de la Orden de los Predicadores, Maestro en santa Theologia", lo que indica que ya en 1571 Mercado había logrado alcanzar el grado de Maestro, que en la orden de Predicadores era la máxima distinción intelectual, como señalan Beuchot e Iñiguez. Al no existir registros en la Universidad de Salamanca respecto a la 
colación de ese grado, parece probable que Mercado lo alcanzase antes de la publicación de la edición sevillana de su obra pero ya en el Colegio de Santo Tomás de Sevilla, donde estuvo de profesor en esos años.

\section{Motivo de su vuelta a México y causa de su muerte}

Resulta poco creíble, como bien señala Sastre Varas, que Mercado se arriesgase por propia decisión a marchar a México a finales de octubre de 1574, viaje que le costó la vida. Una travesía por mar que, por aquellos años, resultaba especialmente peligrosa en invierno. Es muy sorprendente que Mercado viajase por mar en esa época del año cuando había escrito en contra de los comerciantes que ponían en peligro su vida "por un mar océano tan vasto, soberbio y temeroso [...] en el riñón del invierno por noviembre, diciembre y enero, tiempo tan rígido y tempestuoso que aun por tierra no se camina". No parece, por tanto, que Mercado tomase voluntariamente la decisión de viajar a México atravesando el Atlántico en época invernal cuando tan certera y premonitoriamente había escrito contra los viajes oceánicos efectuados por esos meses. Solo puede explicarse esa travesía en pleno invierno por una llamada perentoria de su Orden a la que Mercado respondería con acendrada disciplina pese a sus temores y a su edad, ya avanzada para la época.

Podría esgrimirse alguna razón especialmente relevante para que Mercado viajase a México con tanta premura. Esa motivación quizá pudiera encontrarse en el Archivo General de Indias, en la sección correspondiente a la Audiencia de Panamá. En esa sección se contiene una Real Cédula dirigida "a los oficiales reales de Tierra Firme, para que paguen a la catedral de Panamá la mitad de lo que hubieren valido los frutos de aquel obispado pertenecientes al prelado, durante el tiempo que estuvo la sede vacante por muerte de Fray Tomás de Mercado (el subrayado es nuestro), y se les ordena que, con el parecer del obispo y de la Audiencia, "se gaste en la fábrica de dicha catedral y en cosas del culto divino". Aunque esa Real Cédula está fechada en 1587 es decir, doce años después de la muerte de Mercado- sería posible que, pese a ello, se refiriese a la muerte de Fray Tomás de Mercado acaecida en 1575, pues los asuntos judiciales nunca se han resuelto rápidamente en España y menos aún en aquellos tiempos. Un nombramiento de obispo para Panamá podría haber sido razón suficiente para obligar a Mercado a dirigirse rápidamente hacia América "en el riñón del invierno" y en contra de sus prudentes consejos a los comerciantes.

Sin embargo, la referencia del asiento de esa Real Cédula contiene un grave error en su título y resumen, pues aunque en ellos se cita a Fray Tomás de Mercado la verdad es que se refiere a Fray Manuel de Mercado, de la Orden Jerónima, Obispo de Panamá entre los años 1578 y 1580 y, al parecer, miembro de una familia importante de aquel lugar. Lo de "Tomás" en lugar de "Manuel" es puro error del título y resumen del asiento. Hay que descartar, por tanto, que fuese un nombramiento episcopal la posible causa del precipitado y peligroso viaje en el que perdió la vida Fray Tomás de Mercado.

Más posible parece, aunque tampoco está hoy probado, que Mercado fuese llamado por sus superiores, quizá para ser candidato a una cátedra en la Real y Pontificia Universidad de México, que había comenzado sus enseñanzas en 1553. Como ya se ha expuesto, no parece que Mercado iniciase ese viaje por mar por voluntad propia en los meses que él mismo calificaba como muy arriesgados para la travesía. Si lo hizo fue, muy probablemente, por las perentorias órdenes de sus superiores mexicanos a cuya observancia le obligaban sus votos. Como ya se ha visto, en el transcurso de ese viaje pierde la vida por enfermedad uno de los más preclaros representantes de la Escuela de Salamanca en el siglo XVI. Ese viaje fue, según todos los indicios, el que desencadenó la enfermedad que le causó la muerte.

\section{Resumen necesario: La vida de Fray Tomás de Mercado}

Aclaradas algunas de las incógnitas anteriores en la medida de lo que hoy resulta posible, puede afirmarse que Fray Tomás de Mercado nació en Sevilla en el seno de una acomodada familia, seguramente de comerciantes, en años ya próximos a 1520. Debió estudiar en el Convento de Santo Tomás recibiendo una esmerada educación en la que se incluía altos niveles de latín y de griego. También, aunque con menor seguridad, puede afirmarse que se dedicó inicialmente al 
comercio, bien en nombre propio o -lo más probable- dentro del negocio familiar que se desarrollaba entre Sevilla y México.

Entre 1540 y 1550 se trasladó a la capital de la Nueva España -hoy ciudad de México- seguramente para continuar allí su actividad de comerciante. La sublimación de su espíritu piadoso con la edad o la influencia directa de algún importante suceso personal, desconocido hoy, debió despertar en él una irresistible vocación religiosa, lo que le llevó a ingresar en el Convento de los dominicos de aquella ciudad, recibiendo sus primeras órdenes religiosas en 1553.

En el Convento de México Tomás de Mercado fue discípulo de maestros dominicos formados en la Universidad de Salamanca y, especialmente, de Fray Pedro de Pravia, religioso de gran talla intelectual que llegó a Nueva España en 1550. Pravia había estudiado en la Universidad de Salamanca y procedía del Colegio-Universidad de Santo Tomás de Ávila. Como ya se ha expuesto, con él llegaron también a México Fray Pedro de la Peña y Fray Diego de Osorio, que habían estudiado igualmente en la Universidad salmantina. Todos, pero singularmente el primero, influirían poderosamente en la formación de Mercado en Nueva España, recibiendo de ellos las doctrinas de Domingo de Soto y de otros miembros de la Escuela de Salamanca.

Como ya se ha expuesto, Fray Tomás de Mercado recibió sus primeras órdenes religiosas en 1553 alcanzando el sacerdocio en 1558. Ejerció la docencia en Artes en el Convento de los dominicos de México entre 1558 y 1563 y volvió a España a mediados de 1563, con una corta estancia de días o semanas en Sevilla, para ir a Salamanca antes del inicio de curso de ese mismo año, matriculándose en su Universidad. Muy probablemente la elección de Salamanca para sus estudios fue consecuencia no solo de la fama de esta Universidad sino también de la influencia de los maestros salamantinos que tuvo durante su estancia en el Convento de México y por la relación de dependencia existente entre el Colegio de Santo Tomás de Sevilla y el Colegio de San Esteban de Salamanca.

Por razones hoy desconocidas su primera estancia en Salamanca durará tan solo un curso, pues al finalizar el de 1563-1564 y hasta el inicio del curso 1566-1567 Mercado vuelve a Sevilla, aunque en opinión de Sastre Varas esa vuelta tiene por objeto dedicarse a la enseñanza en el Colegio de Santo Tomás. Su estancia en Sevilla durante ese periodo se desprende de lo que expone en su "Epístola Nuncupatoria". En esa "Epístola" el propio Mercado dice que "Residiendo los años pasados en esta ciudad..." refiriéndose a Sevilla. La "Epístola", como ya se ha comentado, está escrita en 1569 como justificación de la primera edición de la "Suma", aunque también se reproduce en la de 1571, y cuando la escribió residía en Salamanca. A estos efectos, hay que señalar que los dos únicos periodos en que Mercado pudo vivir en Sevilla antes de 1569, aparte de los breves días o semanas que discurren desde su llegada de México en 1563 hasta su viaje a Salamanca a finales de verano o principios de otoño de ese mismo año, son el situado entre el verano de 1564 y el otoño de 1566, en que "desaparece" de los libros de matrícula de la Universidad de Salamanca, o el mucho más lejano -y casi totalmente improbable a efectos de esa bien definida dedicatoria- de su niñez y juventud en Sevilla, antes de su primer viaje a México. Parece, por tanto, que el encargo de Brunengo para escribir la "Suma" tuvo que efectuase entre el verano de 1564 y el otoño de 1566, periodo en que Mercado residió efectivamente en Sevilla.

Como ya se ha expuesto, Fray Tomás de Mercado regresa de nuevo a Salamanca para finalizar sus estudios entre el otoño de 1566 y el verano de 1569 y publica en esta última ciudad en 1569 la primera edición de la Suma. Pero retorna definitivamente a Sevilla y reside de nuevo en esta última ciudad, practicando la docencia en el referido Colegio-Universidad de Santo Tomás, en los cinco años que van desde finales de 1569 a octubre 1574 y recibiendo en ese periodo el grado de Maestro en Sagrada Teología. Durante ese tiempo -y, más concretamente, en 1571publica en Sevilla la segunda y definitiva edición de la Suma. En ese mismo año publica también en esa ciudad y en la misma imprenta los Comentarii e In Dialecticam Aristotelis.

Tres años después de la segunda edición de la Suma, concretamente el 25 de octubre de 1574, Fray Tomás de Mercado, "cargado de la gloria de haber presenciado el formidable éxito de las dos ediciones de su obra", inicia su vuelta a México, embarcándose en Sevilla y falleciendo en el mar, casi al término de ese viaje. Su muerte se produjo por enfermedad en una larga travesía invernal por el Atlántico. A Tomás de Mercado, en expresión de Dávila Padilla, "se lo llevó Dios de una enfermedad a vista del puerto de San Juan de Ulúa" en enero de 1575 a punto de 
finalizar el viaje que había iniciado en Sevilla en octubre de 1574. La muerte de Mercado se debió a alguna enfermedad que probablemente le causara la travesía. Su cuerpo, como era costumbre hasta no hace tanto, fue entregado al mar frente a las costas mexicanas por la tripulación de la nave que le transportaba.

La vida de Tomás de Mercado puede enmarcarse, por tanto, dentro de las circunstancias y fechas que acaban de exponerse. Nace en Sevilla, probablemente algo antes de 1520, dentro de una familia de mercaderes acomodados, lo que le permitió recibir una buena educación en esta ciudad, incluyendo un excelente aprendizaje del latín y del griego. Ejerce la profesión de comerciante en Sevilla, posiblemente dentro del negocio familiar. Viaja a Nueva España en fecha indeterminada, probablemente a mitad de la quinta década del siglo XVI, quizá para ejercer de factor de su familia en aquellas tierras. Ingresa en el Convento de los dominicos de la ciudad de México en 1551 o 1552, sin que se conozcan ni sospechen las circunstancias que le condujeron a adoptar esa importante decisión. Se ordena presbítero en 1558 e imparte docencia en Artes y Teología en su propio Convento de México. Vuelve a Sevilla en 1563, para residir y estudiar en Salamanca entre esa fecha y 1564. En este último año vuelve a Sevilla e imparte docencia como profesor del Colegio de Santo Tomás hasta 1566. Retorna como estudiante a Salamanca en 1566, donde publicará en 1569 la primera edición de su Suma. De nuevo vuelve a Sevilla en ese mismo 1569 dedicándose otra vez a la docencia y alcanza el grado de Maestro en Sagrada Teología en el Colegio de Santo Tomás. Publica en 1571 en Sevilla la segunda y definitiva edición de la Suma así como otras obras con traducciones del griego al latín. Embarca en Sevilla el 25 octubre de 1574 con destino a la ciudad de México y fallece durante la travesía en enero de 1575 a la vista de las costas mexicanas. Eso es todo lo que, resumidamente, puede decirse hoy con razonables fundamentos acerca de la vida de Fray Tomás de Mercado, un gran economista escolástico español del siglo XVI. 